professors, and when the shared nut-

Campusland: A Novel, Scott Johnston, St. Martin’s Press, 2019, pp. 336, \$12.99 hardcover.

Nevergreen, Andrew Pessin, Open Books, pp. 218, \$17.95 softcover.

\section{That's Hilarious: The Campus as Comedy}

\section{Fred Baumann}

The academic comedy is a venerable genre. The reader knows what to expect. Eccentric figures, often recognizable human types, frequently deformed by their intellectual fashions and passions, play off against a reasonable protagonist. Like much satirical comedy, the underlying assumption is the conservative one of a reasonable social and moral order that eventually, as in Shakespeare's plays, reasserts itself. "O Lord, what fools these mortals be" could be the watchword of the genre and of how it provides a typically gentle and ultimately reassuring entertainment for the reasonable reader it presumes.

When, as now however, the educated upper-class audience is itself as likely to be of a kind with the nutty tiness is also a burning angriness,

there is little room for the mild and knowing humor of the classic kind. It's not Pnin or Pictures from An Institution time anymore. The ideas behind Nikole Hannah-Jones's 1619 Project might have started on the campus, but the New York Times and its trusting readers made them the guiding light for the ruling class.

Scott Johnston's Campusland and Andrew Pessin's Nevergreen respond to the new and darker situation in very different ways and with different results. Campusland stays close to the old formula. Its “Devon” is pretty obviously based on Yale, and the farcical tale offers a compendium of many of the well-documented campus outrages and idiocies of recent years. The guileless and old-fashioned scholar who becomes the object of outrages is subjected to, among others, the equivalent of Mattress Girl, of persecution by Title IX apparatchiks, campus and off-campus radicals who cook up phony racism charges, student journalism, and an all too believable cowardly university president. Meanwhile, drink-besotted frat boys, the faux-radical rich, and the faux-radical minorities take their expected turns. The bad guys are 
wholly without redeeming features. The two worst get their highly satisfying comeuppances (and the one who triumphs does so in a way that the reader can easily despise). The good guy comes away wiser and, on the whole, none the worse for wear. It's all highly recognizable, though already a bit out of date. Thus, one of the radicals complains that opposing Israel doesn't have enough traction. The mass academic denunciations of the Jewish state for responding to a barrage of 4,300 rockets from Gaza in spring 2021 suggests that things have changed.

Given the current climate, there is nothing gentle about the satire here. It is "saeva indignatio" all the way and is all the more savage because the incidents recounted are in fact scarcely exaggerated versions of reality, however cartoonish the characters may be. The tone is one of outrage only slightly concealed by the conventions of comic fiction. The comfortable condescension to folly that makes the traditional academic novel a cozy experience is, rightly, entirely lacking here. It is the kind of novel that the readers of Academic Questions are likely to enjoy, at the cost of somewhat heightened blood pressure. I don't know that it will bring enlightenment to many others of the potential readership, since a deliberate endarkenment seems increasingly to be seen as a moral necessity. Still, the novel contains a representative of an older generation that made its money the hard way, by earning it, who might stand for a potential audience of those who haven't yet drunk the poisoned Kool-Aid. I hope he speaks for many of Johnston's readers.

In Nevergreen, Pessin takes a very different, and at first sight, rather strange, approach. Here, the notorious follies of Evergreen State University are the obvious referent. Here too, we have an innocent protagonist to whom bad things happen, this time, oddly, a physician and not a professor. A fan of the study of corpses (again, an oddity, but a significant one), he is invited to lecture at a secluded college on an island, only reachable by ferry boat. Mayhem ensues, though (not too much of a spoiler, I hope), he too survives to tell the tale.

Here the satire, if it is even intended as satire, is closer to allegory than humor. A particularly quarrelsome female academic is called "Peace" and a vile substitute for coffee, made of pomegranate seeds, which is pumped out all over the campus, is called (wait for it), "pomo." The school, even more than “Devon," seems completely uninterested in learning. No one comes to the protagonist's lecture, not even the 
one semi-conservative professor who at first seems sympathetic in what is otherwise a nest of ideological crazies. The students are even more loony in their partisan follies than their elders, and, interestingly, there are far-right wackos (not just one, but two, competing Nazi clubs) as well as the usual run of "progressive" identity groups. That fact tells us that we are not really quite in the world of Campusland. This isn't going to be simply a send-up of today's leftist academia. Bigger game is afoot.

Though it's never stated, the hero seems to have arrived just in time for Halloween and its beloved Nevergreen traditions. Here the novel takes a sharp turn into a different genre, namely horror. Before you know it, the doctor is running for his life (or at least he thinks he is) pursued (he thinks) by a crowd of cannibal students straight out of The Lord of The Flies. Pessin makes open references not just to Golding but to Orwell, since Pessin's protagonist undergoes his own improbable version of a Title IX hearing in Room 101, the room where Winston Smith was famously tortured into betraying Julia in 1984. And, unsurprisingly perhaps, the protagonist is called, a la Kafka, “J.” Indeed, as the novel goes on, the references become more recondite and grimmer.
The turn to the conventions of the horror genre (think for instance of that classic short story "The Most Dangerous Game"), accompanied by constant references to literary sources, seems paradoxical. The horror genre is meant to suck you in, to scare you out of your wits, while the little, learned references tell you that it's all "meta," all somewhat tongue in cheek. So what is Pessin up to?

Like the classic academic novel, Campusland keeps its distance. We are outside looking at the silly people and their antics. Pessin, however, takes you inside, into the horrific experience of an innocent visitor to a madhouse where the lunatics have taken over because the authorities have gone mad first (cf. Poe's “The System of Dr. Tarr and Professor Fether”). J becomes (or sees himself as having become), the designated victim of their madness. That has become an increasingly typical experience in our days of cancel culture and is never more frightening than when it happens at a college or university. That is where the nightmare of losing, overnight, one's friends, one's career, one's direction, and sometimes one's sense of who one is, would seem to be the most direct, immediate, and intense. It is not the subject of comedy, and if not exactly of tragedy either, one that deserves understanding 
and compassionate attention. Going there shows that Pessin, under the trappings of satire where the satirist stands securely outside the objects of mockery, is doing something else as well, something darker and a lot less funny.

I am not entirely sure why Pessin makes the narrator unreliable and perhaps overly fearful. What has happened to professors, students, and sometimes staff (like the security guard who was hung out to dry at Smith College), who have been unjustly persecuted isn't attributable to their paranoia. My guess is that he wants you to understand how someone in that situation begins to doubt his own sanity. But while he takes you inside the mind of a reasonable person exposed to the insane logic of his tormentors, he also-and unlike the classic horror story-wants to keep you at least a bit outside the experience, so the reader can analyze and understand both it and the forces that are causing it. Both the inclusion of campus Nazis and Kafka's “K” becoming "J" suggests the "Jewish Question" is being hinted at, though it never explicitly surfaces. (There was an “unfortunate incident" some years ago that is mentioned throughout but no one dares explain.). The uncertainty of just how far this misanthropy has gone, how bad it really is, or how far it could go, is in fact part of the lived experience of those of us who are watching anxiously or are even caught up in the events.

With Campusland you quickly know what's on offer and can settle in for an amusing, if angry, ride. Nevergreen is a more disturbing and unsettling read. There is plenty of material for savage indignation, but Pessin doesn't really seem interested in whipping it up. The craziness of the contemporary academy is almost taken for granted, not something to be overly outraged about. But I wonder if that very fact isn't part of Pessin's point: the escapades described in his story aren't any more frightening than the follies that we read about every day. For to the extent that they have become the new normal, they have numbed us to their colossal injustice and hypocrisy; to the extent that yelling about them seems pointless and even immature, they have deformed our own sensibilities.

If so, then the two novels have a potentially complementary relation. Pessin takes you farther inside the experience of living in a crazy world than it might, on the whole, be healthy to go. Johnston reminds you of what was once understood to be and is still in fact the sane and normal-outsideview of the corrupt and dishonest poseurs who increasingly have taken 
over the academy today. There is no hint of justice in Nevergreen. Survival is as good as it gets. In Campusland, normalcy is at least partly restored, and justice is largely done. The more surreal novel is, alas, in many places probably more realistic than the overtly more realistic-even in caricature form-one. But you need both. Tacitus said the purpose of history was to praise the good and blame the bad. Novels can justly do that too, but they can also take us inside experiences, even those where things become so incalculable that the coordinates of praise and blame seem to be lost.

Still, the foregoing seems to me a little too neat. I think that Pessin too wants to do more than just show you the madness of the age. The experience of losing one's bearings, even to the point of perhaps exaggerating the dangers one faces, is itself comprehensible in moral terms precisely because it is the experience of demoralization. The follies of "Nevergreen College" are demoralizing not just to the main character and obvious victim but to every student, administrator, and faculty member we meet. They are humans diminished into images of themselves, into gestures, abstractions, labels. They have either chosen this degradation or accepted it as prudent and necessary. Where in
Campusland the hypocrites are phonies, grifters, cynics out to get ahead, in Nevergreen they are genuine head cases, lost souls. The lack of interest in serious learning (nineteenth century American literature is the example), is a source of indignation and contempt in Campusland. In Nevergreen it seems more like a state of damnation, of loss of self, all the more radical in being replaced by a phony and superficial catalog of "identities."

Will either or both of these novels prompt change? It's not a question one might justly ask of, say, Madame Bovary, but I think it's a fair one to ask about those that offer praise and blame, as even Pessin ultimately seems to. My guess is that Campusland will have its effect but mostly with those who already agree. Nevergreen will puzzle readers more than it will either confirm or convert. But I think that for some readers the disturbance of the mind and feelings it might cause will loosen up the glib certainties of the day and provoke real thought. In the end, that might be more important. 